\title{
A ATUAÇÃO JURÍDICA DO ESTADO BRASILEIRO NA MIGRAÇÃO HAITIANA A PARTIR DO ESTADO DO ACRE (2010-2015)
}

Tayson Ribeiro Teles*

\section{Resumo}

Neste escrito dialogamos sobre a atuação estatal brasileira nos eventos relacionados à migração massiva de haitianos que chegaram ao país a partir do estado do Acre, no começo de 2010, e prosseguiram utilizando essa porta de entrada até o final de 2015. Privilegiando trabalhos que já trataram da temática em focos sociológicos, identitários, políticos e culturais, como Albuquerque (2014), Santos (2014) e Paula (2013), nossa abordagem mira no foco sociojurídico da questão. Analisamos a Ação Civil Pública n. ${ }^{\circ}$ 0000723-55.2012.4.01.3000, proposta pelo Ministério Público Federal no Acre, e a Ação Civil Pública n. ${ }^{\circ}$ 0000384-81.2015.5.14.0402, de 2015, interposta pelo Ministério Público do Trabalho na 14a Região (Acre e Rondônia). Os resultados demonstram ter havido um misto de ineficiência administrativa e legalismo exacerbado por parte do Estado brasileiro, que demorou para perceber a complexidade e a dimensão da questão migratória haitiana.

Palavras-chave: Atuação jurídica. Estado brasileiro. Migração haitiana. Acre.

* Doutorando e Mestre em Linguagem e Identidade pela Universidade Federal do Acre - UFAC. Docente do Magistério Federal - EBTT de Economia e Gestão de Finanças e Comércio do Instituto Federal do Acre - IFAC. E-mail: tayson.teles@ifac.edu.br 


\section{Introdução}

A partir de 2010, após o Haiti passar por terremotos devastadores, milhares de haitianos buscaram refúgio no Brasil. As catástrofes ambientais, porém, foram apenas o epicentro, a centelha, para a migração internacional haitiana. Antes dos terremotos, o Haiti já passava por inúmeras crises econômicas e conflitos políticos, lavando grande parte de sua população ao marasmo e à fome.

O Brasil foi um dos principais destinos do fluxo migratório erigido a partir do Haiti. Os haitianos vieram para o Brasil em busca de trabalho e melhores condições de vida. Muitos passaram a trabalhar no Brasil e enviar dinheiro para seus parentes que ficaram no Haiti. Os haitianos viram no Brasil, em preparativos para a Copa do Mundo de 2014, a chance de encontrar empregos em grandes obras. Outro fator que atraiu os haitianos para o Brasil foi o já existente laço entre os dois países pelo Brasil ter liderado, a partir de 2004, uma missão civil-militar da Organização das Nações Unidas (ONU), que objetivou estabilizar politicamente o Haiti.

Os imigrantes haitianos chegaram ao Brasil passando pelo Equador, Peru e Bolívia, ingressando no território nacional principalmente pela região norte, especialmente o estado do Acre. A cidade acreana mais afetada foi Brasileia, na fronteira com o Departamento de Pando (Bolívia). Após ingressarem pelo Acre, a maior parte dos haitianos migrou para o Sul e Sudeste, possivelmente em busca de melhores condições de emprego e vida.

Conforme a Polícia Federal Brasileira, em 2010 havia 595 haitianos do Acre. Em 2014, esse número saltou para 30 mil e, entre 2010 e 2015, estimase que passaram pelo Acre mais de 70 mil haitianos. A situação no Acre foi caótica com a migração haitiana. As cidades acreanas não foram capazes de absorver o grande número de migrantes, havendo falta de alimentos, aumento de doenças, violência. Muitos migrantes haitianos foram marginalizados, vítimas de preconceitos e explorados no mercado informal de trabalho.

No contexto social:

Habituados com a presença de estrangeiros "branquinhos de olhos azuis" falando em inglês, português, espanhol e ou "portunhol", nas duas últimas décadas, eis que de repente, entre o final de 2010 e início de 2012, as populações de algumas cidades situadas na fronteira tri nacional Brasil/Peru/Bolívia surpreendem-se com a chegada de um novo tipo social: centenas de homens, mulheres e crianças negras falando uma língua estranha, o crioulo haitiano. Ao contrário dos primeiros, os "branquinhos", que na maioria das vezes encontraram e encontram as "fronteiras abertas" e as "boas vindas" e ou "las bien venidas" por parte das autoridades governamentais, os negros haitianos encontraram as "fronteiras fechadas" e não receberam nem as "boas vindas" no território brasileiro e tampouco "las bien venidas" no Peru e na Bolívia (PAULA, 2013, p. 188). 
Como narra Albuquerque (2014, p. 172), desde 2010:

Num deslocamento de milhares de quilômetros, homens, mulheres e crianças atravessam o continente, partindo de Porto Príncipe ou Santos Domingo, passando pelo Panamá, Equador e Peru ou Bolívia, até alçar a Amazônia brasileira pelas cidades de Tabatinga (Amazonas) ou Assis Brasil e Brasileia (Acre). Nessa parte da Amazônia a viagem é interrompida e os deslocados são encerrados num "abrigo" ou no que estamos denominando de "curral de refugiados" à espera de permissão e documentos para residir, trabalhar e estudar no Brasil. Uma espera marcada pela morosidade e contradições dos órgãos estatais, responsáveis pela "imigração", pela falta de infraestrutura básica de alojamentos e alimentação, mas, também, pela desconfiança e toda forma de estranhamentos.

Sendo que neste processo migratório houve, e ainda está havendo, muito preconceito, o qual:

[...] se manifesta na forma de barreiras sanitárias; indiferença e deboche com os "estrangeiros"; invisibilidade de milhares de negros; longas discussões diplomáticas entre países cujos governantes "não desejam assumir o problema haitiano"; fechamento de fronteiras ou seu deslocamento simbólico e um excessivo discurso de instituições estatais, organizações não governamentais e empresas privadas imbuídas de um "espírito humanitário" e disposição de "abraçar" os "irmãos" caribenhos. [...] os haitianos são, sintomaticamente, tratados apenas como "mão de obra" para empresários e outros particulares interessados nas muitas formas e possibilidades de exploração da “carne mais barata do mercado" (ALBUQUERQUE, 2014, p. 174).

Nessa direção, "os milhares de homens e mulheres que alcançaram as cidades de Brasileia, Assis Brasil, Epitaciolândia e Rio Branco, no estado do Acre, não receberam uma atenção que visasse compreender e minimizar seus problemas" (SANTOS, 2014, p. 9). Apenas instituições filantrópicas e poucos gestores do estado do Acre, inicialmente, ofereceram efetivas ajudas aos haitianos que ingressaram nessa unidade federativa a partir de 2010. O Estado brasileiro mesmo, a República Federal, oficialmente, demorou mais tempo para agir em prol dos migrantes.

Nas palavras de Paula (2013), o descaso direcionado aos haitianos pela maioria das autoridades acreanas e brasileiras, de um modo geral, (apenas geral e não absoluto) parece, entre várias coisas, ter a ver com a ridícula ideia de que o Acre é uma "porta de saída" do Brasil e não de entrada. "A rodovia inter-oceânica parece ilustrar bem [...] que a 'porta de saída' nem sempre pode ser $[. .$.$] 'entrada' [. .$.$] as motivações [...] derivam [...] de interesses de$ natureza mercantil [...] ela recebeu uma conotação de 'saída' de mercadorias para o mercado externo via oceano Pacífico” (PAULA, 2013, p. 192). 
Pensar sobre os movimentos estatais, em bases sociojurídicas, de adjuvação aos migrantes afrocaribenhos, principalmente os haitianos, que ingressaram no Brasil pelo Acre, ocorridos entre 2010 e 2015, é nosso objetivo neste artigo. Por exploração bibliográfica revisional e qualitativa ater-nos-emos a analisar, jurídica e sociologicamente, as duas ações judiciais/jurídicas mais relevantes intentadas no período. Tratamos da Ação Civil Pública (ACP) n.o 0000723-55.2012.4.01.3000, proposta, em 2012, pelo Ministério Público Federal no Acre (MPF/AC), por meio do Procurador da República Anselmo Henrique Cordeiro Lopes, e da Ação Civil Pública (ACP) n. ${ }^{\circ}$ 0000384-81.2015.5.14.0402, interposta, em 2015, pelo Ministério Público do Trabalho no Acre (MPT/AC), por meio do Procurador-chefe do Trabalho na $14^{\text {a }}$ Região (Acre e Rondônia) Marcos Gomes Cutrim.

\section{A Ação Civil Pública n. ${ }^{\circ}$ 0000723-55.2012.4.01.3000 - Ministério Público Federal no Acre}

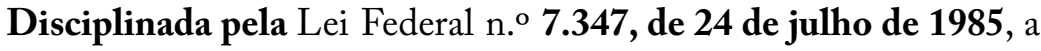
Ação Civil Pública pode ser proposta pelo Ministério Público, Defensoria Pública, União, estados, Distrito Federal, municípios, autarquias, empresas públicas, fundações ou sociedades de economia mista e associações que lidem com a proteção ao patrimônio público e social, ao meio ambiente, ao consumidor, à ordem econômica, à livre concorrência, aos direitos de grupos raciais, étnicos ou religiosos ou ao patrimônio artístico, estético, histórico, turístico e paisagístico, desde que constituída a pelo menos 1 (um) ano.

Todavia, dentre tais legitimados, observa-se ser mais comum o Ministério Público (MP) ingressar no Judiciário com esse tipo de ação, porquanto cabe ao parquet a proteção dos interesses da sociedade de modo lato. $\mathrm{O}$ próprio constituinte originário lembrou disso ao afirmar, no Art. 129, inciso III, da Constituição da República Federativa do Brasil de 1988 (CRFB/88), ser função institucional do MP "promover o inquérito civil e a ação civil pública, para a proteção do patrimônio público e social, do meio ambiente e de outros interesses difusos e coletivos".

A exemplo disso, o petitório em questão foi subscrito pelo Procurador da República, Anselmo Henrique Cordeiro Lopes, tendo sido erigido em 25 de janeiro de 2012. Consoante o Procurador narra no enredo da peça propositória, a ACP fora a atitude última tomada pelo Ministério Público Federal no Acre objetivando que a União (governo federal) começasse a prestar assistência aos "refugiados" haitianos no estado do Acre, porquanto apenas o governo do Acre estava envidando alguns esforços na ajuda aos migrantes.

Anteriormente à elaboração da $\mathrm{ACP}$, já havia sido produzida Recomendação Ministerial (Recomendação n. ${ }^{\circ}$ 20/2011 - Procuradoria da 
República no Acre - PRAC), a qual sugeria à União, entre outros aspectos, que a República assumisse a gestão da assistência humanitária que estava sendo prestada aos "refugiados" haitianos na fronteira tríplice do Brasil, no Acre. Tendo a União descumprido a recomendação. Nesse sentido, também em 2011 fora construído Inquérito Civil n. ${ }^{\circ}$ 1.10.00.000134/2011-90, o qual objetivava acompanhar o tratamento dispensado, pelas autoridades administrativas competentes, aos haitianos que se encontravam no Brasil, visando a garantir o respeito aos seus direitos humanos fundamentais. Portanto, a ACP em tela não foi ato inicial, mas o deslinde de todo um contexto de omissão do Estado federal brasileiro.

A ACP fora distribuída no Fórum da Seção Judiciária Federal de Rio Branco, capital do Acre, integrante da Justiça Federal da 1. ${ }^{a}$ Região, tendo caído, por sorteio, sobre a competência do Juiz Federal Guilherme Michelazzo Bueno, da 1a Vara Federal desta cidade. Em decisum in limine, o magistrado proveu parcialmente os pleitos ministeriais contra a União, para que fossem garantidos os direitos humanos dos imigrantes haitianos que chegavam ao Brasil em busca de trabalho e condições dignas de sobrevivência, após os terremotos que devastaram o Haiti em 2010.

Ao decidir liminarmente, o magistrado colocou o processo sob sigilo ("segredo de justiça") para evitar perturbações internacionais. A Polícia Federal foi intimada a cumprir a parte da decisão que lhe coube, a qual era não barrar mais os haitianos na fronteira do Acre. Após, a Advocacia Geral da União (AGU) recorreu e a decisão liminar do magistrado foi reformada, em Brasília, pelo Tribunal Regional Federal (TRF) da $1^{\text {a }}$ Região, ainda em 2012. Em 2013, de revés, curiosamente, o próprio magistrado, ao produzir a sentença final do feito, mudou de ideia, e não proveu os pedidos do MPF/ AC em definitivo, revogando sua decisão inicial.

Porém, para entendermos este desfecho faz-se mister analisarmos percucientemente a demanda e seu desenrolar. $\mathrm{O}$ que pleiteava o $\mathrm{MPF} /$ $\mathrm{AC}$ e o que alegou a União? O MPF/AC, como já frisado anteriormente, objetivava desobstaculizar a entrada de haitianos no Brasil, dado o caráter emergencial da vinda desses imigrantes. Para o Órgão Ministerial, a expedição de documentos e concessão de "refúgio", que estavam sendo processos muito "burocráticos", deveriam ocorrer em rápidos intervalos de tempo, visto que os migrantes apenas queriam trabalhar no Brasil, a fim de manter suas famílias que no Haiti tinham ficado.

Alegou o MPF/AC que o governo federal, além de "burocratizar" a entrada dos haitianos no Brasil, por meio das fronteiras do Acre, e impedir, com a força da Polícia Federal, que novos migrantes ingressassem no país, não estava prestando quaisquer assistências aos "refugiados". Segundo o MPF/AC, a União, após ver o elevado quantitativo de migrantes que estavam vindo para o Brasil, emitiu Resolução Normativa n. ${ }^{\circ}$ 97, por meio 
do Conselho Nacional de Imigração, na qual delimitou como o máximo de 1.200 o número de haitianos que poderiam ingressar anualmente no Brasil.

Estava o governo estadual do Acre tendo elevados gastos na condução dos procedimentos de assessoramento humanitário aos "refugiados" e, desse modo, depreende-se que o objeto da ACP era o desejo do MPF/AC, enquanto órgão responsável por lutar por tratamento humano minimamente digno a qualquer pessoa humana/física que esteja no território brasileiro, de que a União tomasse a frente da ajuda humanitária ofertada, bem como que o governo federal parasse de "expulsar", via Polícia Federal, haitianos que chegavam ao Brasil.

Além do que, queria o parquet federal que fosse regularizada a situação documental dos haitianos, a fim de que estes pudessem trabalhar e viver normalmente no Brasil; que cessassem quaisquer ameaças de deportação a haitianos residentes no país e que fosse proibida a limitação do quantitativo de haitianos a entrar no Brasil. Para tal, alegou o MPF/ $\mathrm{AC}$ que os haitianos, bem como qualquer pessoa do mundo, antes de serem haitianos, são pessoas e merecem ser tratadas conforme preconizam os tratados de direitos humanos internacionais dos quais o Brasil é signatário.

Segundo a ACP, os direitos humanos, conforme descrito na Carta Internacional de Direitos Humanos (Declaração Universal dos Direitos Humanos de 1948, Organização das Nações Unidas - ONU), acolhidos pelos Estados Democráticos, como parte de seus sistemas internos, são universais, sobrepondo-se ao direito convencional e servem, inclusive, como limite à soberania dos países, conforme reconhecido atualmente pela doutrina internacional. De acordo com a petição vestibular da Ação, o instituto do "refúgio" não está isolado no Direito Internacional e deve ser compreendido como instrumento de garantia do exercício pleno dos direitos humanos. Assim, aduziu o MPF/AC que mesmo a legislação brasileira se atualizou e ampliou a possibilidade de concessão de refúgio ao incluir na Lei Federal n. ${ }^{\circ}$ 9.474/97 a condição de refugiado a todo aquele que "devido a grave e generalizada violação dos direitos humanos, é obrigado a deixar seu país de nacionalidade e buscar refúgio em outro país"(Art. 1. ${ }^{\circ}$, inciso III).

A ACP teve como suporte/fundamentação, também, a alegação de que o direito ao "refúgio" não pode ficar estaticamente ligado ao fundamento da perseguição política, mas, tal como os direitos humanos, deve ser dinamicamente entendido, tendo em vista as novas investidas e ameaças aos direitos humanos, como nos casos de crises políticas, econômicas e tragédias ambientais ou naturais. Principalmente, se tais eventos são potencializados pelo caos social da região, como foi o caso específico do Haiti, que viveu perturbações político-sociais durante décadas mesmo antes dos grandes terremotos de 2010, levando seus cidadãos exatamente à situação de vítimas de graves violações dos direitos humanos. 
A obrigação do Brasil, de atender e acolher os haitianos, segundo o texto da Ação, consistia também em atender à própria $\mathrm{CRFB} / 88$, que expressamente sujeita o Brasil à "prevalência dos direitos humanos" (Art. $4^{\circ}$, inciso II), bem como obriga o país a guiar-se pela solidariedade humana em relação aos povos da América Latina, de acordo com o parágrafo único

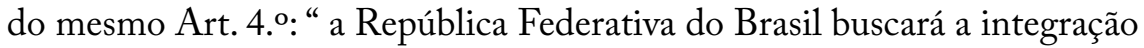
econômica, política, social e cultural dos povos da América Latina, visando à formação de uma comunidade latino-americana de nações”.

$\mathrm{O}$ enredo da Ação narra que servidores do MPF/AC realizaram, no dia 25 de novembro de 2011, diligências in loco na tríplice fronteira do Acre, objetivando verificar a verossímil situação dos cidadãos haitianos que se encontravam em Brasileia e Epitaciolândia e, após tal visita, fora confeccionado relatório diligenciativo, o qual enfatizou, entre outras questões, que:

Já entraram no território nacional pelo Estado do Acre (Municípios de Brasileia e Assis Brasil) aproximadamente 1.300 haitianos; 2) Tais indivíduos, ao ingressar no território nacional, após requererem a concessão de refúgio na Polícia Federal, acabam se fixando por longos períodos no Município de Brasileia; 3) Os imigrantes fixamse por longos períodos no Município de Brasileia em razão da demora na expedição da documentação pertinente (CPF e Carteira de Trabalho); 4) Aos haitianos inicialmente alocados em ginásios esportivos de Epitaciolândia e Brasileia (dada a grande quantidade de pessoas) foi disponibilizada pelo governo local hospedagem em hotel (Hotel Brasileia); 5) O aludido hotel se encontra superlotado com, aproximadamente, 10 pessoas por quarto, sendo muitas pessoas obrigadas a se acomodar em colchonetes em meio às bagagens que se acumulam nas áreas comuns do hotel, excedendo em muito a capacidade do hotel, que pode suportar normalmente apenas 100 indivíduos; 6) O Governo do Estado do Acre vem arcando sozinho com os gastos referentes à ajuda humanitária aos haitianos (refeições diárias, assistência médica etc.), tendo sido omisso o Governo Federal quanto ao auxílio de sua competência; 7) Entre os haitianos instalados na cidade de Brasileia, há mulheres grávidas e crianças; 8) As crianças e as mulheres grávidas necessitam de cuidados especiais, não tendo os Municípios de Brasileia e de Epitaciolândia a estrutura mínima adequada para a prestação suficiente dos serviços de saúde requeridos; 9) Segundo declarações prestadas por agente da Secretaria de Estado de Justiça e Direitos Humanos do Acre, a água para consumo utilizada pelos haitianos não é de boa qualidade, bem como não há recipientes adequados para seu armazenamento (garrafas de água sanitária, por exemplo, são reaproveitadas para tanto), sendo também precárias as instalações sanitárias do hotel; 10) Existem vários imigrantes acometidos de enfermidades como AIDS, hepatite e outras doenças sexualmente transmissíveis; 11) Em virtude da ausência de distribuição periódica e em quantidade suficiente de material de limpeza pessoal e preservativos, o risco de transmissão de doenças entre os haitianos (e destes para brasileiros) é 
potencializado; 12) O serviço de saúde disponibilizado aos haitianos é prestado no posto de saúde do Município de Brasileia, porém este não comporta o crescente número de indivíduos que solicitam atendimento, dada a falta de estrutura mínima, inclusive de recursos humanos; 13) Relativamente aos pedidos de refúgio, essenciais para que os haitianos possam seguir para outras localidades no país em busca de emprego, a quantidade de atendimentos realizados pela Polícia Federal não vinha sendo satisfatória, pois são feitos, em média, somente 8 atendimentos por dia, sendo que, dada a quantidade de imigrantes que aguardam a liberação da documentação (CPF e Carteira de Trabalho - CTPS) e os que chegam diariamente ao Município, seriam necessários, pelo menos, 20 atendimentos diários; 14) A demora na conclusão das providências administrativas que autorizam a emissão de CPF e Carteira de Trabalho gerava frustração e acúmulo na quantidade de estrangeiros que, sendo obrigados a permanecer na ociosidade, aglomeram-se no Município de Brasileia, ficando este e o Estado do Acre com o ônus de prestar o auxílio humanitário aos imigrantes (MINISTÉRIO PÚBLICO FEDERAL NO ACRE, 2012, p. 7-8).

Outrossim, analisando os aspectos sociológicos que estão incrustados na construção jurídica que basifica o pedido de concessão de "refúgio" aos migrantes haitianos formulado pelo MPF/AC, percebe-se que foram de fundamental importância na sustentação da tese defendida as seguintes ideias: a) os haitianos são seres humanos! Isto é, o MPF/AC alegara que, independentemente de sua condição nacional, o ser humano deve ter sua dignidade reconhecida e preservada, sendo este um fundamento da República Brasileira, observável no Art. $1 .^{\circ}$, inciso III da Carta Política de 1988; b) todo ser humano, seja qual for sua nacionalidade, sua condição física, seu modo de agir (sua cultura), necessita de condições mínimas para viver - condições estas que estavam sendo negadas pelo governo federal do Brasil aos haitianos que chegavam ao país; c) o humanismo e os sentimentos de fraternidade são aspectos sociológicos imanentes à condição humana. A humanidade somente evoluiu à sua atual condição graças à união entre os homens.

Nesse rumo, o MPF/AC afirmou, peremptoriamente, que seria injusto o Estado brasileiro oferecer as condições mínimas de vivência aos brasileiros residentes no país (se é que ele oferece) e não oferecer aos haitianos, que provisoriamente estavam, também, sobre a proteção do Estado, tendo em vista que se encontravam em solo brasileiro. O Procurador, assinante da ACP, objetivando, por fim, aclarar a necessidade de a União prestar assistência aos haitianos e oferecer-lhe "refúgio", pormenorizou vários dispositivos legais nacionais e internacionais, dos quais o Brasil é signatário, afirmando que não havia espaço para a discricionariedade do Estado em decidir se ia ou não respeitar os direitos humanos dos haitianos. Consoante o Procurador, os migrantes que se encontravam no Brasil, pelo mero fato 
de serem seres humanos (pessoas no sentido literal) mereciam proteção de todos os seus direitos humanos fundamentais, e por estarem no território brasileiro não apenas mereciam, mas deviam ter a assistência do Estado, tivessem ou não entrado no território nacional de forma documentada.

Como dissemos, o magistrado julgador da ACP inicialmente, em 2012, deferiu o pleito e ordenou que a União assumisse o comando da ajuda humanitária aos haitianos em seus caminhos migratórios a partir do Acre. Após essa decisão, porém, não houve imediata e efetivamente impactos positivos para os migrantes que já estavam e os que chegavam ao Brasil pelo Acre. Começou um longo período confuso de "transição" entre o "término" dos trabalhos do governo estadual do Acre e o "início" das ações federais. Além disso, a União, logo em seguida, conseguiu reformar a decisão liminar junto ao TRF da $1 .^{\text {a }}$ Região e a situação voltou ao status quo (somente o Acre tomando a frente das ações "humanitárias").

Vejamos notícias jornalísticas sobre o período, as quais demonstram a celeuma de atritos entre estado do Acre e governo federal sobre a questão haitiana:

Os haitianos que entraram ilegalmente no país deverão receber visto humanitário que thes garanta a permanência no país por cinco anos. O documento poderá ser renovado por igual período e, dependendo da situação, ser trocado pelo visto permanente. De acordo com o secretário nacional de Justiça, Paulo Abrão, a regularização será destinada apenas aos imigrantes haitianos. "O conjunto de medidas especiais que o Estado brasileiro adota para fins de regularização dentro do nosso território está destinado aos haitianos, em virtude da responsabilidade diplomática e histórica que o Brasil tem com o povo do Haiti", disse o secretário, em entrevista à imprensa na cidade de Rio Branco, antes de ir para Brasileia [ambas no Acre] (REDE BRASIL: 13.04.2013).

A situação dos imigrantes haitianos que todos os dias cruzam a fronteira com o Peru e chegam a Brasileia, no Acre, pode virar pauta de discussão na OEA (Organização dos Estados Americanos). A ONG Conectas pediu nesta sexta-feira a realização de uma audiência temática na Comissão Interamericana de Direitos Humanos para debater a questão e discutir temas como o que chamou de "jogo de palavras" do governo brasileiro na emissão de vistos aos imigrantes que chegam ilegalmente ao país com ajuda de coiotes. "É insalubre, desumano até. Os haitianos passam a noite empilhados uns sobre os outros, sob um calor escaldante, acomodados em pedaços de espuma que algum dia foram pequenos colchonetes", relata João Paulo Charleaux, coordenador de Comunicação da Conectas. "O Acre está exaurido". É assim que o secretário de Direitos Humanos do Acre, Nilson Mourão, classifica a situação em Brasileia, por onde, segundo ele, já passaram milhares de haitianos. "Desde o início desse fluxo de imigração, mais de dez mil haitianos já passaram aqui no Acre. Todos foram acolhidos e receberam atenção humanitária. Essa é 
uma questão de ordem federal e o governo do Acre e a prefeitura de Brasileia estão sobrecarregados", disse (BBC BRASIL: 23.08.2013).

$\mathrm{Na}$ próxima terça-feira, 21, uma reunião interministerial entre representantes da Casa Civil da Presidência da República, ministério da Saúde, da Justiça e do Governo do Acre pretende elaborar uma solução definitiva para os imigrantes haitianos que utilizam o Acre para entrar no Brasil. "Em dezembro do ano passado, o Ministério da Justiça acordou com o nosso governo que o tempo máximo de permanência do imigrante em Brasileia seria de três dias. Infelizmente, o Ministério não alcançou essa meta”, cobrou o governador Tião Viana em declaração feita após audiência nesta quinta-feira no Ministério da Justiça (O ESTADÃO/Hoje em Dia: 16.01.2014).

Sem avisar a prefeitura de São Paulo e o governo federal, o governo do Acre enviou haitianos para a cidade. Abandonados, eles dependem de ajuda para se alimentar. "Ontem saíram duas ou três mulheres e chegaram mais 25 imigrantes", conta o padre italiano Paolo Parise, diretor do Centro de Estudos Migratórios (CEM) da Missão Paz. Os haitianos estão alocados de forma improvisada em um dos salões da Missão Paz. Eles dormem em colchões, um do lado do outro, e recebem cobertores por causa do frio durante a noite. Não têm, no entanto, como tomar banho. E comem com a ajuda de moradores do bairro no entorno ou quando outros imigrantes que já estão fixados na região se mobilizam para ajudar. "Sábado alguns imigrantes peruanos vão fazer um sopão para eles. Com a ajuda dos haitianos que já vivem em São Paulo há algum tempo fizemos um jantar na segunda. Foram necessários 110 pratos", explica Parise (CARTA CAPITAL: 24.04.2014).

A crise que eletrifica as relações entre São Paulo e Acre atingiu o apogeu no início da madrugada desta quarta-feira (30). Os governadores Geraldo Alckmin (PSDB) e Tião Viana (PT), que sempre foram afáveis um com o outro, trocaram insultos em público. Chamado por Alckmin de "irresponsável" por enviar refugiados haitianos para a capital paulista sem aviso prévio, Viana abespinhouse. "Indago a esse sujeito que governa São Paulo: tem veio de racismo ou intolerância aos irmãos haitianos em sua atitude?" (UOL NOTÍCIAS: 30.04 .2014$)$.

O governador do Acre, Tião Viana, anunciou, nesta sexta-feira (17), que o Ministério da Justiça deverá assumir o trabalho de acolher e encaminhar para outros estados os imigrantes, na maioria haitianos, que utilizam o estado como porta de entrada para o Brasil. De acordo com o gestor, o estado não possui mais condições de realizar esse trabalho. Viana esteve reunido com representantes dos Ministérios Públicos Estadual e Federal, além dos secretários de Desenvolvimento Social (Sedens) e Justiça e Direitos Humanos (Sejudh) para falar sobre a decisão. Ele também anunciou a medida em seu perfil no Twitter (G1 ACRE: 17.04.2015). 
"De 2010 a março de 2015, 35.938 estrangeiros chegaram de forma ilegal no Brasil pela fronteira do Peru com o Acre. O Governo do Acre, por razões humanitárias, tudo que pôde fez para prestar sua solidariedade aos imigrantes, todavia, exauriu-se no caso", disse Sebastião Viana [Governador do Acre]. Ao todo, já foram gastos cerca de $\mathrm{R} \$ 23$ milhões com os imigrantes. O Estado usou dos próprios cofres mais de $\mathrm{R} \$ 10$ milhões, enquanto a União repassou $\mathrm{R} \$$ 9,8 milhões, e ainda há $\mathrm{R} \$ 2,8$ milhões em despesas a serem pagas entre o aluguel da chácara que serviu de abrigo e o transporte usado para levar os imigrantes aos destinos que eles almejavam. Essas viagens já foram canceladas há mais de um mês, uma vez que o Acre é apenas a porta de entrada para eles. A situação atual do abrigo na Chácara Aliança, onde ficam os imigrantes, tornou-se insustentável. Com capacidade para menos de 300 pessoas, hoje o abrigo conta com 800 . E todo dia chegam de 60 a 70 imigrantes (AC24HORAS: 18.04.2015)

O governo do Acre decidiu unilateralmente entregar para a administração federal a responsabilidade pela gestão do Abrigo dos Imigrantes, instalado em Rio Branco para acolher os milhares de estrangeiros - a maioria haitianos - que entram ilegalmente no estado para depois se dirigir a outras regiões do país. $\mathrm{O}$ anúncio foi nesta sexta-feira (24), em Plenário, pelo senador Jorge Viana (PT-AC). Ao justificar a medida, ele disse que o estado não pode continuar assumindo "responsabilidade estranha" a suas competências. Salientou que questões de imigração em massa são da responsabilidade da União e mesmo de organismos da Organização das Nações Unidas - ONU (PAINEL POLÍTICO: 27.04.2015).

O Ministério da Justiça suspendeu, a partir desta terça-feira (19), o transporte de imigrantes haitianos do Acre para a cidade de São Paulo. Os estrangeiros só voltarão a ser levados à capital paulista após o governo federal, do Acre, e a prefeitura de São Paulo estabelecerem novo esquema para o transporte de imigrantes. Nesta terça, o prefeito de São Paulo, Fernando Haddad, disse que a cidade não foi avisada com antecedência do envio de imigrantes haitianos. De acordo com o padre Paolo Parisi, da Paróquia Nossa Senhora da Paz, que abriga imigrantes e refugiados, mais de 40 haitianos chegaram a São Paulo de domingo (17) para segunda-feira (18), vindos do Acre, e mais 40 na última noite (ECOACRE NOTÍCIAS: 20.05.2015)

Durante entrevista coletiva na manhã desta sexta-feira, 20, na Casa Civil, o governador do Acre, Sebastião Viana, anunciou o fim da rota de imigração para o Brasil que tinha como porta de entrada a fronteira acreana com o Peru. De 2010 até este ano, mais de 43 mil pessoas de 15 países, a maioria haitianos, entraram no Brasil pelo Acre, segundo dados da Secretaria de Direitos Humanos. Viana destacou que a maioria dos imigrantes saiu do Acre com destino ao sul do país e que agora eles estão escolhendo como destino o Chile. “30\% foram para São Paulo e outros 70 ou mais para o sul do Brasil. A imigração parou de acontecer por aqui [Acre], mas tá tendo agora uma migração reversa. Estão vindo de lá (Haiti) e estão indo para o 
Chile não para o Haiti. Quero agradecer e deixar essa informação da missão cumprida. Não perdemos o controle da situação e vencemos porque acreditamos que o gesto humanitário era mais importante do que uma função defensiva e de escusa por parte do governo", salientou (AC24HORAS: 20.05.2016). (Grifos nossos)

Observando as reportagens sobre fatos ocorridos entre 2010 e 2016, percebe-se que houve verdadeiro embate entre o governo do Acre e o governo federal. Um direcionava para o outro as funções/ obrigações de ajudar, enquanto o tempo passava e mais e mais haitianos ingressavam no Brasil, eram tratados como coisas, desumanizados. O Acre alegava falta de recursos e existência de legislação federal sobre o tema migração. A União usava da retórica, dizendo que ia assumir a causa em breve. Era patente o amadorismo de quem governava o país no trato de questão internacional tão relevante que é a ajuda humanitária a pessoas advindas de situações tão sofríveis como os haitianos. São curiosas, nesse contexto, as palavras do então governador do Acre que obtemperou "não ter o Acre perdido o controle da situação e que a missão foi cumprida" (AC24HORAS: 20.05.2016).

$\mathrm{Na}$ verdade, o Acre perdeu o controle da situação. O Brasil foi pego de surpresa com o fluxo migratório haitiano. Mas, tal fato não poderia ser surpresa a uma prudente interpretação quando lembramos que o Brasil não presta assistência eficiente sequer aos seus nacionais. Afora isso, acreditamos que a situação foi caótica pelo fato de grande parcela dos trabalhos terem de fato sido direcionados para o governo acreano. O Acre foi “acuado". Viu milhares de migrantes chegarem, alterarem o funcionamento das cidades de Assis Brasil, Brasileia e Epitaciolândia e viu o governo federal demorar a acordar para a questão. Foi algo ululante num Brasil que sequer reconhece o Acre como estado, um Brasil que considera o Acre o fim do mundo, um lugar que somente tem mato, indígenas e bichos, um lugar que não existe.

$\mathrm{O}$ magistrado que deferiu liminar na $\mathrm{ACP}$ em 27 de janeiro de 2012, obrigando a União a assumir a causa assistencial, foi o mesmo que, talvez inspirado na reforma de sua decisão pelo TRF da $1 .^{\mathrm{a}}$ Região, em 14 de janeiro de 2013, proferiu sentença final na Ação Civil Pública revogando a própria liminar e desobrigando a União de oficialmente prestar, de forma exclusiva e absoluta, assistência aos migrantes haitianos. Na sentença, o Juiz Federal afirmou haver naquele momento, 1 (um) ano após o ingresso da ACP pelo MPF/ AC, perda superveniente do objeto da Ação, porquanto a União já estava ajudando os haitianos desde 2010 com algumas ações.

Aduziu o decididor judicial que não havia notícias de estar a União negando assistência médica e social aos haitianos em suas instituições 
(federais). O magistrado, para exemplificar, citou a Portaria n. 101 de 2012 do Ministério da Saúde que, por meio deste regramento, enviou ao Acre mais de 1 (um) milhão de reais para custeio da saúde dos migrantes. O Juiz Federal também lastreou em seu decisum doutrina sobre refugiados e afirmou que somente poder-se-ia pensar em violação aos direitos humanos, como alegara o MPF/AC, se o Estado-país do Haiti estivesse totalmente (de forma absoluta) sem condições de prover direitos aos seus cidadãos.

Disse o magistrado que o Brasil somente poderia oferecer refúgio aos haitianos caso a) o Haiti possuísse total incapacidade de ação ou mesmo não fosse mais um Estado Democrático de Direito; b) que faltasse naquele país uma paz estável e durável; e c) que houvesse um reconhecimento internacional sobre efetiva, grave e generalizada violação a direitos humanos havendo naquela nação. $\mathrm{O}$ Juiz asseverou claramente na página 6 de sua sentença: "não sigo a lição que admite a existência de 'refugiados ambientais"'. Para o julgador, o Haiti mesmo sendo um país em (re)construção, recuperando-se de várias crises políticas, econômicas e catástrofes ambientais, não poderia repelir sua obrigação de cuidar de seus nacionais.

O Juiz estampou que inicialmente deferiu liminar obrigando a União a assumir a ajuda aos migrantes baseado na urgência da questão e no princípio jurídico do "não-rechaço", previsto na legislação brasileira, ou seja, a ideia de que, em causas internacionais, não se pode ignorar a necessidade de uma ajuda emergencial, mas se pode, contudo, após o passar do tempo e melhor interpretação analisar profundamente a questão e tomar a decisão estatal que convier, isto é, que retoricamente convergir com a letra fria, e geralmente cruel, da lei. O magistrado finalizou sua decisão dizendo que, grosso modo, o Brasil já estava cumprindo sua função internacional ao, obedecendo ao "não-rechaço", não deportar os haitianos que aqui chegavam.

Vê-se que, então, para o juiz, o Brasil deveria ajudar os haitianos, oferecer-lhes documentos, oportunidades de laboro, mas isso não era "uma obrigação", um ato compulsório e totalizante; não deveria o país esquecer de seus nacionais e cuidar enfaticamente dos haitianos. Algo como: ok podem passar por aqui, podem ficar também, caso queiram, mas o que há para vocês é somente isso aqui. O magistrado disse que a União não estava descumprindo nenhuma normal internacional simplesmente, pois os haitianos não poderiam ser considerados refugiados. Ao final de seu texto, o juiz revogou sua liminar, julgou improcedente a demanda e extinguiu o processo. Conforme consulta processual, o MPF/AC recorreu e desde 02/09/2013 o feito está no TRF da 1. a Região com status de julgamento de Apelação. 


\section{A Ação Civil Pública n. ${ }^{\circ}$ 0000384-81.2015.5.14.0402 - Ministério Público do Trabalho no Acre}

No curso dessa problemática haitiana, houve outra Ação Civil Pública (ACP), desta feita a identificada em epígrafe, a qual fora intentada pelo Ministério Público do Trabalho no Acre (MPT/AC), em 2015. O MPT/AC ingressou com o pleito em 25 de maio de 2015 exigindo que o governo federal assumisse a gestão dos abrigos onde estavam os imigrantes, na maioria haitianos, que utilizavam a fronteira do estado do Acre com o Peru para ingressar no Brasil desde 2010. Basicamente o mesmo pedido feito na $\mathrm{ACP}$ de 2012 pelo MPF/AC, com a diferença que agora o MPT/AC trazia à tona aspectos trabalhistas presentes na questão haitiana. Esta nova $\mathrm{ACP}$ foi distribuída para a 2a Vara do Trabalho de Rio Branco.

"Queremos a federalização do abrigo de estrangeiros em Rio Branco [Acre] e também o combate ao tráfico internacional de trabalhadores, coibindo a ação de coiotes e evitando que eles sejam submetidos à situação de trabalho escravo como já foi constatado pelo Ministério Público do Trabalho entre 2013 e 2015", narrou o Procurador-chefe do MPT nos estados do Acre e Rondônia, Marcos Gomes Cutrim. A Ação exigia que a União assumisse a responsabilidade pelo transporte interestadual dos haitianos por meio de aviões da Força Aérea Brasileira ou do fretamento de ônibus, para que se evitasse a superlotação nos abrigos, até aquele momento ainda mantidos pelo governo do Acre.

A ação pediu uma indenização de $\mathrm{R} \$ 50$ milhões por danos morais coletivos in faciem da União. $\mathrm{O}$ dinheiro deveria ser empregado, segundo o MPT/AC, na promoção de políticas públicas para o acolhimento dos imigrantes que possuíssem visto humanitário no estado e mais uma multa diária de $\mathrm{R} \$ 100$ mil cada vez que as recomendações forem descumpridas. Segundo explanou o Procurador-chefe do MPT, entre 2013 e 2015, o parquet trabalhista engendrou uma investigação sobre a situação dos imigrantes que utilizavam a rota ilegal de imigração. "Constatou-se que existe uma rede de coiotes trabalhando desde o Haiti até a entrada do Brasil pela fronteira do Acre, agenciando e traficando trabalhadores haitianos, senegaleses e de ao menos outras 13 nacionalidades", ressaltou.

Acreditava o MPT/AC que se houvesse um aumento no quantum de vistos concedidos para os imigrantes, poder-se-ia enfraquecer a ação dos coiotes. "Se houver melhoria na embaixada brasileira no Haiti e o aumento na emissão de vistos, esses trabalhadores não vão se submeter a ação de coiotes. Isso ocorre atualmente porque é o caminho mais rápido para que eles saiam de seus países de origem e ingressem no Brasil sem documentos", disse o Procurador. O MPT/AC requeria, também, que os imigrantes fossem inclusos no Sistema Nacional de Emprego (Sine). Para 
o MPT/AC esta seria uma forma de evitar que essas pessoas acabassem aceitando empregos em situação análoga a de escravidão. De acordo com Cutrim, existiam naquele momento 75 inquéritos civis em tramitação no Órgão Ministerial trabalhista, investigando as condições de trabalho de imigrantes haitianos em diversos estados.

OProcurador-chefe do MPT/AC disse, ainda, que durante a investigação foram detectados casos de empresas que iam ao Acre para contratar imigrantes e os selecionavam pela idade, porte físico, espessura da canela e condições da genitália. Cutrim disse que não havia explicação para esse tipo de exigência. "Do ponto de vista científico não há embasamento nenhum. Parece que era a mera vontade de discriminar e selecionar. O que se percebia é que 'os abrigos mais pareciam senzala do século XIX. Eram os mesmos métodos de contratação”, afirmou. Em 5 de junho de 2015, a Juíza do Trabalho Titular da 2a Vara do Trabalho de Rio Branco-Acre, Silmara Negrett Moura, em decisão liminar, acatou a ACP integralmente e determinou que União assumisse o transporte dos estrangeiros desde a fronteira com a Acre até os estados para onde os haitianos fossem encaminhados para trabalhar.

A magistrada determinou que o governo federal assumisse as políticas migratórias para trabalhadores haitianos e africanos e deu prazo de 15 dias para que a União assumisse os abrigos de acolhimento para imigrantes estrangeiros que entravam no país em busca de trabalho pela fronteira com o estado do Acre. No decisum in limine, a magistrada determinou que a União deveria garantir atendimento médico aos trabalhadores estrangeiros, a ser feito por profissionais especializados, com conhecimento das doenças endêmicas das regiões da procedência dos imigrantes. Também devia o governo federal fazer o encaminhamento dos imigrantes para empregos por meio do Sine, visando prevenir a vitimização dos trabalhadores estrangeiros e a colocação em empregos de qualidade duvidosa, bem como reduzir o tempo de permanência dos imigrantes nos abrigos.

A magistrada insculpiu uma multa de 100 mil reais a ser paga pela União, por obrigação que deixasse de cumprir, cujo valor deveria ser investido em projetos indicados pelo MPT/AC para as cidades de Brasileia, Assis Brasil, Epitaciolândia e Rio Branco, com a finalidade de compensar as lesões sofridas por estas cidades com o impacto social motivado pelo ingresso dos imigrantes. Também condenou a União na indenização de 50 milhões de reais. Enfim, proveu todos os pedidos do MPT/AC.

Vale lermos alguns trechos da decisão:

[...] o Autor [MPT/AC] juntou farta documentação, em quase duas mil páginas. A par da robusta prova documental, é histórico que o Haiti é um País que desde o início dos anos 90 atraiu missões da Organização dos Estados Americanos (OEA) e das Nações Unidas (ONU), cujas políticas visavam à diminuição da miséria e 
da violência que assolavam a nação haitiana. Contudo, o fruto, ainda incipiente, deste imenso esforço foi consumido em 2010, quanto o Haiti sofreu um gravíssimo terremoto, que matou mais de 200 mil haitianos, feriu em torno de 300.000 e deixou em torno de três milhões de desabrigados no País, que até hoje vive a reconstrução e conta com milhares de haitianos vivendo em acampamentos em torno da capital Porto Príncipe, enfrentando dificuldades como a escassez de recursos para a reconstrução e a epidemia de cólera, cenário que gerou o êxodo de haitianos rumo ao Brasil em busca de trabalho e sustento, sendo, a maioria de homens, [...] recebidos no Brasil ao albergue da Resolução Normativa no 97 do CNIg, com visto concedido por razões humanitárias nos termos do art. 16 da lei 6.815/80, com validade de 5 anos. O quadro criado no Estado do Acre com a chegada dos trabalhadores imigrantes está descrito no Ofício enviado pela Secretaria de Estado de justiça e Direitos Humanos do Estado do Acre ao Ministério Público do Trabalho, juntado aos autos [...], demonstrando a dificuldade da União em gerir a questão. Insta salientar que esta Magistrada, como moradora da cidade de Rio Branco, presencia todos os dias o fervilhar da questão migratória destes trabalhadores, tendo presenciado um grupo caminhando à pé pela BR 317 fazendo a distância entre Brasileia e Rio Branco (cerca de 219 km!), verificando que estes trabalhadores se acumulam em pontos da capital aos montões, aguardando o destino incerto de serem encaminhados para outros Estados da Federação, de maneira que, no Estado do Acre, em especial nas cidades de Brasileia, Epitaciolândia e Rio Branco, é público e notório que tais trabalhadores, bem como os demais de outras nacionalidades, entram no Brasil em busca de trabalho. Toda sociedade acreana, em especial aquelas das cidades mencionadas, vivenciam a precariedade da gestão dada ao problema, de resto, estampada nos ofícios encaminhados pelo Excelentíssimo Governador do Estado do Acre, Sr. Tião Viana, que enfatizou que as medidas tomadas pela União "estão longe de fazer frente às necessidades" e "executadas com muito atraso e desconsiderando a gravidade do problema humanitário enfrentado". Também restou demonstrado nos autos que até estas medidas, embora tímidas e executadas com atraso, deixaram de ser implementadas pelo Estado do Acre, que concluiu pela impossibilidade de manutenção do quadro "por conta da ausência da devida atenção por parte de alguns órgãos federais", registrando que a situação dos abrigos é insustentável e declarando-se sem condições de garantir de forma permanente a continuidade das ações humanitárias então implementadas, comunicando, assim, a suspensão destas ações a partir do dia 2/5/2015, deixando a questão, classificada como um "desafio", ao encargo da União. O desdobramento desta caótica situação atinge também outras partes do País, como se observa no Ofício emitido pela Procuradoria-Geral do Estado do Rio Grande do Sul, que noticia a preocupação do governo gaúcho com o destino dos trabalhadores trazidos de Brasileia, em razão das denúncias à Comissão de Cidadania e Direitos Humanos da Assembleia Legislativa sobre condições precárias de trabalho e inclusive análogas à de escravo a que estavam sendo submetidos os trabalhadores haitianos trazidos para o sul do Brasil por diversas 
empresas, tendo constatado que efetivamente havia "condições muito precárias e limítrofes com condições análogas a de trabalho escravo". Enfim, mesmo esta análise preliminar revela a gênese do problema, que é a diáspora destes trabalhadores rumo ao Brasil, bem como o desdobramento inicial surgido, que é a recepção destes trabalhadores no estado do Acre, depois a segunda etapa que é o caminho percorrido em solo brasileiro até o emprego, geralmente em outros estados da Federação, e ainda, no final desta cadeia, a condição de trabalho de muitos deles de forma degradante e até análoga à condição de escravo. O arcabouço jurídico existente para subsumirse à situação relatada foi minudentemente abordado na petição inicial, instando mencionar a Declaração Universal dos Direitos do Homem (arts. $2^{\circ}, 6^{\circ}, 13,15,23,25,28$ e 29), as Convenções 88 e 97 da OIT (art. $2^{\circ}$ e 6º), a Recomendação 198 da OIT, a Convenção americana dos Direitos Humanos, o Protocolo de San Salvador, o Pacto Internacional dos direitos Civis e Políticos da ONU (arts. $2^{\circ}$, $5^{\circ}, 9^{\circ}$ e 26), o Pacto Internacional dos Direitos Econômicos, Sociais e Culturais (arts. $6^{\circ}$ e $7^{\circ}$ ) e a Constituição Federal (arts. $1^{\circ}, 3^{\circ}, 5^{\circ}$, $7^{\circ}$ e 170) [...] Ressalte-se que estas medidas de urgência visam, além de proteger os trabalhadores imigrantes, estender-se como medida protetiva de todos os brasileiros acreanos, ante à devida recepção e encaminhamento destes trabalhadores, bem como em face da regular manutenção de suas necessidades enquanto perdurar a estadia nos abrigos, desonerando o Estado do Acre, já tão penalizado por suas dificuldades particulares, de gerir uma questão nacional, com viés internacional, cuja responsabilidade suportou por tantos anos, com restrito apoio. Protege também a todos os brasileiros de outros estados da Federação, que receberão estes trabalhadores devidamente encaminhados, para vagas de trabalho disponíveis, sem nenhum viés de precarização de direitos trabalhistas, cujo mal, uma vez instalado, atinge, inexoravelmente, imigrantes e nacionais. Desta forma, deferese liminarmente, porque preenchido o requisito do perigo da demora [...] (JUSTIÇA DO TRABALHO NO ACRE, 2015, p. 10-13). (Grifos nossos)

Entrementes, naquele momento, para análise do mérito da $\mathrm{ACP}$, a douta Juíza também designou audiência preliminar. $\mathrm{O}$ feito prosseguiu sendo instruído durante todo o restante de 2015 e em 23 de fevereiro de 2016 a União e o estado do Acre, por meio de sua Procuradoria-Geral do Estado (PGE/AC) assinaram acordo, aceito pelo MPT/AC, no qual a União se comprometeu a assumir todos os procedimentos relacionais à assistência aos haitianos.

\section{As implicações das Ações Civis Públicas in faciem da ineficiência do Estado brasileiro}

Após a contextualização das ACP's n. ${ }^{\circ}$ 0000723-55.2012.4.01.3000, de 2012, proposta pelo Ministério Público Federal no Acre, e n. ${ }^{\circ} 0000384-$ 
81.2015.5.14.0402, de 2015, proposta pelo Ministério Público do Trabalho no Acre, a grande indagação é: por que houve tanta confusão nessa situação dos haitianos? Por que vimos o MPF/AC impetrar ACP requerendo que a União assumisse a causa, Ação que teve liminar julgada procedente em 2012, mas que depois, em sede de sentença, em 2013 eximiu a União de tal incumbência? Por que vimos em 2015 o MPT/AC intentar outra ACP, desta feita junto à Justiça do Trabalho, a qual também fora deferida como liminar para obrigar a União a assumir a questão haitiana, União esta que assinou acordo definitivo com o estado do Acre somente em 2016, aceitando ser de fato a esfera competente para cuidar da situação haitiana? Por que duas ACP's com resultados diametralmente opostos e no final um mero acordo?

Por que foram necessários mais de 5 (cinco) anos para que tivéssemos um desfecho na questão? Por que a União não assumiu a causa ainda em 2010 ou 2012, quando do seu agravamento? Por que precisamos, nós, os cidadãos brasileiros e os haitianos, esperar entre 2010, quando os primeiros afrocaribenhos começaram a ingressar no Acre, e 2015, quando, segundo notícias, praticamente cessou a entrada de migrantes por esse estado, e houve a última ACP, do MPT/AC, e o referido acordo? Por que a União somente assinou acordo, aceitando sua competência legal, após praticamente estarem todos os haitianos vindos regularizados, trabalhando e tendo condições de se manterem sozinhos no Brasil e após diminuir drasticamente a vinda de haitianos para o país? Por que na ACP do MPF/AC o Juiz Federal Guilherme Michelazzo Bueno desobrigou a União e na ACP do MPT/ AC a Juíza do Trabalho Silmara Negrett Moura demonstrou, talvez, mais humanidade deferindo o pleito e obrigando a União a assumir a causa? Duas pessoas usando o mesmo Direito tomaram decisões tão opostas, por que razão? Seria a Justiça Trabalhista mais sensível justamente por lidar com a situação de vidas de trabalhadores?

Cremos que a resposta para tudo isso se resume a descaso e, por que não, desumanidade! Todo o deslinde do caso fora resultante de ineficiência do Estado brasileiro em lidar com causas complexas e de grande monta. O brasileiro, de modo geral, costuma sempre deixar tudo para última hora. Esquecemo-nos de agir, compreender nossas realidades, intervir nelas, sermos humanos. Decidimos não alimentar aos haitianos que ao Brasil chegaram, porquanto não alimentamos nem a nós mesmos. Todos nós fomos preconceituosos em relação aos haitianos. Equivocamo-nos, pois somos nós o Estado brasileiro. Se o governo federal não agiu, deveríamos todos nós termos agido.

Mas:

[...] fica evidente que a reação e as atitudes do governo brasileiro em relação aos haitianos sempre encontrou respaldo nas instituições 
e na sociedade que continuam assistindo tudo de forma conivente. As imagens de milhares de mulheres e homens "amontoados" numa espécie de "curral de refugiados" - em condições subumanas, na cidade de Brasileia, "disputando" refeições - em quantidade e qualidade duvidosas -, aguardando documentos para lhes assegurar uma sub-cidadania controlável, reduzidos à mão-de-obra disponível a empresários que os submeterão a algum tipo de análise/avaliação para verificar se estão aptos aos trabalho, entre outras apontam para a absoluta participação da sociedade no tratamento dispensado a esses afrocaribenhos (ALBUQUERQUE, 2014, p. 193). (Grifos nossos)

\section{Considerações Finais}

Analisamos, aqui, a atuação estatal brasileira nos eventos relacionados à migração de haitianos que chegaram ao Brasil, a partir do estado do Acre, no começo de 2010, e prosseguiram utilizando essa via de acesso até o final de 2015. Mirando no foco sociojurídico da situação, analisamos a Ação Civil Pública n. ${ }^{\circ}$ 0000723-55.2012.4.01.3000, de 2012, proposta pelo Ministério Público Federal no Acre, e a Ação Civil Pública n. ${ }^{\circ}$ 0000384-81.2015.5.14.0402, de 2015, interposta pelo Ministério Público do Trabalho na 14a Região (Acre e Rondônia).

Os resultados demonstram ter havido um plexo de ineficiência administrativa e legalismo exacerbado por parte do Estado brasileiro, que demorou para perceber a complexidade e dimensão da questão migratória haitiana. "A política externa brasileira frisa seu papel de protagonista solidário com o povo haitiano, fato que contribui para o Brasil conquistar maior representação internacional e se destacar enquanto potência latinoamericana"(MEJÍA et al., 2015, p. 2), mas isso não passa de mera retórica. Somente os haitianos sabem o que passaram ao ingressarem no Brasil. Somente os acreanos sabem como tiveram suas vidas alteradas pela presença haitiana.

É notório que "os haitianos vitimados pelos efeitos dos 'desastres naturais' e transgressões territoriais, encontram no país que 'gerencia' a ocupação de sua pátria [o Brasil comanda ações militares de paz no Haiti] violações de direitos [...] de magnitude similar. Emigram de uma situação de domínio do colonialismo externo para uma dominada pelo colonialismo interno" (PAULA, 2013, p. 204-205).

Portanto, nesse contexto da questão haitiana:

[...] observa-se no Brasil a reedição do processo histórico imprescindível ao capitalismo mundial, que impõe aos Estados nacionais, políticas de reestruturação produtiva, contribuindo para a modelagem das correntes migratórias mundiais desenhadas pelos trabalhadores expropriados, em busca de 
novas possibilidades de sobrevivência. $O$ debate está aberto e é necessário para acompanhar os desdobramentos [...] e os desenhos dos movimentos dos trabalhadores na construção da história (MAMED; LIMA, 2015, p. 55).

Por fim, em aspectos processuais, talvez o problema da questão haitiana tenha ocorrido também, e precipuamente, porque a tramitação de Ações Civis Públicas, como as intentadas pelo MPF/AC e MPT/AC seguem o rito ordinário, ou seja, funcionam como um processo comum, longo, "não urgente", o que talvez tenha permitido a demora e descaso da União, que foi protelando a questão o quanto e quando pode, a exemplo da dilação de prazo que conseguiu em 2015, de 15 para 120 dias, para assumir financeiramente as ações humanitárias (BAPTISTELA; LANGNER, 2015, p. 14). O Estado brasileiro deveria ter agido em benefício dos haitianos logo a partir do início da imigração acontecida. Assim, estaria o Brasil fazendo valer os tratados internacionais que versam sobre os direitos humanos.

\section{Referências}

AC24HORAS. União passará a administrar ações de imigração no estado do Acre. Notícia de Jornal Online. Disponível em: <http://www.ac24horas.com/2015/04/18/ governo-do-estado-passara-administracao-da-imigracao-para-a-uniao/>. Acesso em: 27 nov. 2019.

. Acre anuncia fim da rota de imigração. Notícia de Jornal Online. Disponível em: <http://www.ac24horas.com/2016/05/20/governo-anuncia-fim-da-rota-deimigracao-no-acre/>. Acesso em: 27 nov. 2019.

ALBUQUERQUE, Gerson Rodrigues de. Diásporas de afrocaribenhos para a Amazônia acreana. In: ALBUQUERQUE, Gerson Rodrigues de; ANTONACCI, Maria Antonieta (Orgs.). Desde as Amazônias: colóquios. Rio Branco: NEPAN, 2014, p. 171-210.

BRASIL. Constituição da República Federativa do Brasil de 1988. Brasília: Congresso Nacional, 1988. Disponível em: <http://www.planalto.gov.br/ccivil_03/ constituicao/constituicaocompilado.htm>. Acesso em: Acesso em: 27 nov. 2019.

.Lei Federal n. ${ }^{\circ}$ 7.347, de 24 de julho de 1985 (Lei da Ação Civil Pública). Brasília: Presidência da República, 1985. Disponível em: <http://www.planalto. gov.br/ccivil_03/leis/L7347orig.htm>.Acesso em: 27 nov. 2019.

.Lei Federal n. 9.474, de 22 de julho de 1997 ("Estatuto dos Refugiados"). Brasília: Presidência da República, 1997. Disponível em: <http://www.planalto. gov.br/ccivil_03/leis/L9474.htm>. Acesso em: 27 nov. 2019.

BAPTISTELA, Tiago; LANGNER, Ariane. A (in)eficiência do direito processual coletivo como instrumento de proteção do direito bumano de imigrar. Anais do XII Seminário Internacional de Demandas Sociais e Políticas Públicas na Sociedade Contemporânea, Porto Alegre, CEPEJUR, 2015, p. 1-16. Disponível 
em: <http://online.unisc.br/acadnet/anais/index.php/sidspp/article/view/13083>. Acesso em: 27 nov. 2019.

BBC BRASIL. ONG leva caso de imigrantes haitianos no Acre à OEA. Notícia de Jornal Online. Disponível em: <http://www.bbc.com/portuguese/ noticias/2013/08/130819_acre_haitianos_conectas_oea_mm>. Acesso em: 27 nov. 2019.

CARTA CAPITAL. Um desastre humanitário no centro de São Paulo. Notícia de Jornal Online. Disponível em: <https://www.cartacapital.com.br/sociedade/um-desastrehumanitario-no-centro-de-sao-paulo-9065.html>.Acesso em: 27 nov. 2019.

ECOACRE NOTÍCAS. Ministério da Justiça suspende transporte de haitianos do Acre para demais capitais. Notícia de Jornal Online. Disponível em:

$<$ http://www.ecoacre.net/topo/ministerio-da-justica-suspende-transporte-dehaitianos-do-acre-para-demais-capitais/>. Acesso em: 27 nov. 2019.

G1 ACRE. Governador do AC diz que imigrantes são responsabilidade da União. Notícia de Jornal Online. Disponível em: <http://g1.globo.com/ac/acre/ noticia/2015/04/governador-do-ac-diz-que-imigrantes-sao-responsabilidade-dauniao.html>. Acesso em: 27 nov. 2019.

JURUÁ ONLINE. MPT quer que União assuma haitianos e pague indenização de R\$ 50 mi. Notícia de Jornal Online. Disponível em: <http://www.juruaonline.net/ acre/mpt-quer-que-uniao-assuma-haitianos-e-pague-indenizacao-de-r-50-mi/>. Acesso em: 27 nov. 2019.

JUSTIÇA FEDERAL NO ACRE. Ação Civil Pública n.o 000072355.2012.4.01.3000. Consulta processual. Disponível em: $<$ http://processual.trf1. jus.br/consultaProcessual/processo.php?trf1_captcha_id=b38af6feee244ace60ad0f 456647222b\&trf1_captcha=8mjb\&enviar=Pesquisar\&proc $=00007235520124013$ 000\&secao=AC. Acesso em: 27 nov. 2019.

JUSTIÇA DO TRABALHO NO ACRE. Ação Civil Pública n. 000038481.2015.5.14.0402. Consulta processual. Disponível em: <http://www.trt14.jus. br/documents/10157/cd333a37-c8bc-4043-b43c-3824279bb109>. Acesso em: 27 nov. 2019.

MAMED, Letícia Helena; LIMA, Eurenice Oliveira de. Trabalho, precarização e migração: recrutamento de haitianos na Amazônia acreana pela agroindústria brasileira. Novos Cadernos NAEA, Belém, v. 18, n. 1, jan-jun. 2015, p. 33-64. Disponível em: <http://www.periodicos.ufpa.br/index.php/ncn/ article/view/2079>. Acesso em: 27 nov. 2019.

MEJÍA, Maragarita Rosa; CAZAROTTO, Rosmari; GRANADA, Daniel. Migração haitiana no Brasil: análises de um processo em construção a partir de um estudo de caso. Anais do VII Seminário Internacional sobre Desenvolvimento Regional - Rio Grande do Sul. Universidade de Santa Cruz do Sul - UNISC, 2015, p. 1-18. Disponível em: <http://online.unisc.br/acadnet/anais/index.php/ sidr/article/view/13379>. Acesso em: 27 nov. 2019.

MINISTÉRIO PÚBLICO FEDERAL NO ACRE. Ação Civil Pública que pede reconhecimento do refúgio aos cidadãos haitianos no Brasil. Rio Branco: Procuradoria da República no Acre, 2012, p. 1-28. Disponível em: <http://www. prac.mpf.mp.br/atos-do-mpf/acp/acphaitianos/view>. Acesso em: 27 nov. 2019. 
O ESTADÃO/Hoje em Dia.Adiada para terça resolução do caso dos haitianos no AC. Notícia de Jornal Online. Disponível em: <http://hojeemdia.com.br/primeiroplano/pol\%C3\%ADtica/adiada-para-ter\%C3\%A7a-resolu\%C3\%A7\%C3\%A3odo-caso-dos-haitianos-no-ac-1.234819>. Acesso em: 27 nov. 2019.

PAINEL POLÍTICO. Acre repassa ao governo federal responsabilidade de imigrantes. Notícia de Jornal Online. Disponível em: < https://painelpolitico.com/acre-repassaao-governo-federal-responsabilidade-de-imigrantes/>. Acesso em: 27 nov. 2019.

PAULA, Elder Andrade de. Entre desastres e transgressões. A chegada dos imigrantes haitianos no "Reino deste mundo Amazônico". Novos Cadernos NAEA, Belém, v. 16, n. 2, dez. 2013, p. 197-206. Disponível em: <http://www.periodicos.ufpa.br/index. php/ncn/article/view/1124>. Acesso em: 27 nov. 2019.

REDE BRASIL. Governo vai conceder visto humanitário a haitianos ilegais no país. Notícia de Jornal Online. Disponível em: <http://www.redebrasilatual.com.br/ cidadania/2013/04/governo-vai-conceder-visto-humanitario-a-haitianos-ilegaisno-pais>. Acesso em: 27 nov. 2019.

SANTOS,Armstrong da Silva.Haitianos naAmazônia sul-ocidental: identidades e narrativas em trânsito. Dissertação de Mestrado (Mestrado em Linguagem e Identidade). Rio Branco: Universidade Federal do Acre, 2014, 129p. Disponível em: <https://posletrasufac.com/banco-de-dissertacoes/>. Acesso em: 27 nov. 2019.

UOL NOTÍCIAS. Caso dos haitianos: Alckmin e Viana se insultam. Notícia de Jornal Online. Disponível em: <http://josiasdesouza.blogosfera.uol.com. br/2014/04/30/caso-dos-haitianos-alckmin-e-viana-se-insultam/>. Acesso em: 27 nov. 2019.

Submetido: 22/03/2019.

Aceito: 15/12/2019. 


\title{
THE LEGAL ACTION OF THE BRAZILIAN STATE IN HAITIAN MIGRATION FROM THE STATE OF ACRE (2010-2015)
}

\begin{abstract}
In this paper, we talk about the Brazilian state action in the events related to the massive migration of Haitians who arrived in the country from the state of Acre at the beginning of 2010 and continued using this gateway until the end of 2015. Privileging works that have already addressed the theme in sociological, identity, political and cultural focuses, such as Albuquerque (2014), Santos (2014) and Paula (2013), our approach focuses on the legal focus of the issue. We analyzed Public Civil Action No. 0000723-55.2012.4.01.3000, of 2012, proposed by the Federal Public Ministry in Acre, and Public Civil Action No. 0000384-81.2015.5.14.0402, of 2015, filed by the Public Prosecutor's Office In the 14th Region (Acre and Rondônia). The results show that there was a mix of administrative inefficiency and exaggerated legalism on the part of the Brazilian State, which took time to realize the complexity and dimension of the haitian migratory issue.
\end{abstract}

Keywords: Legal action. Brazilian state. Haitian migration. Acre.

\section{LA ACUACIÓN JURIDICA DEL ESTADO BRASILEÑO EN LA MIGRACIÓN HAITIANA A PARTIR DEL ESTADO DEL ACRE (2010-2015)}

\begin{abstract}
Resumen
En este escrito dialogamos sobre la actuación estatal brasileña en los eventos relacionados con la migración masiva de haitianos que llegaron al país desde el estado de Acre a principios de 2010 y prosiguieron utilizando esa puerta de entrada hasta el final de 2015. Privilegiando trabajos que ya trataron de la temática en focos sociológicos, identitarios, políticos y culturales, como Albuquerque (2014), Santos (2014) y Paula (2013), nuestro enfoque mira en el enfoque sociojurídico de la cuestión. Los resultados demuestran haber habido una mezcla de ineficiencia administrativa y legalismo exacerbada por parte del Estado brasileño, que tardó para percibir la complejidad y dimensión de la cuestión migratoria haitiana.
\end{abstract}

Palabras-clave: Actuación jurídica. Estado brasileño. Migración haitiana. Acre. 